\section{Military Technical College \\ Kobry El-Kobbah, \\ Cairo, Egypt}

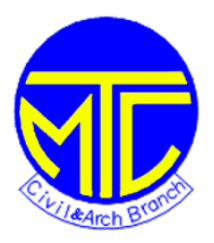

$10^{\text {th }}$ International Conference on Civil and Architecture Engineering ICCAE-10-2014

\title{
Empirical Model for Prediction the Impact of Change Orders on Construction Projects- Sports Facilities Case Study
}

\author{
Dr. Ibraheem Abdel -Rasheed Professor of Construction Project Management \\ Dr.Mohammed Ahmed El-Mikawi Associate Professor of Construction Project Management \\ Eng. Mohammed El-Sayed Abdel-Hamid Saleh
}

\section{Abstract:}

In general, Change Orders in construction projects pose a serious problem possibly impacting quality, cost, and time of the projects. Youth Sport Center Construction Project (YSCCP) in Egypt as an example of the sports construction industry have faced quit a number of Change Orders leading to cost increae and time extensions. (9) Groups of youth sport center construction projects experienced (151) Change Orders. These groups of projects were utilized to contemplate different causes of Change Orders, the frequency of their occurrence, the responsible of this Change Order, the cost of Change Orders, and the time extension attributed to these Change Orders. This issue was analyzed to measure the reasons and effects of change orders. This paper presents the relationship between project cost and construction time within construction projects. This paper presents a time-cost relationship model valid for Youth Sport Center construction project. The model included Change Orders categories; Work disciplines (Civil work, Electrical work, Structural work, Architectural work) and Project parties (Owner, Consultant, Contractor, Local Authorities).

Keywords: Change Order, Construction, Impact, Cost, Time, Sports Facility

\section{Introduction:}

Change refers to any event those results in modification of the original project scope, execution time, or cost of work. Construction Change Orders are one of the most widely experienced Change Orders; however, many projects are plagued by severe construction disputes triggered by such changes. Change Orders strain the relationships of the owners, engineer, contractors, subcontractors, and others involved in the construction process as well as add cost and schedule delay. Changes on one 
project can also affect other unrelated projects by trying up resources that are committed elsewhere. Negative relationships between the parties are another byproduct of changes on a project. In an attempt to reduce cost over runs, time delays, and disputes in projects some researchers have examined change order management change order practices and developed recommendations regarding the management of change orders during construction life cycle. Little research however has addressed the relationship between project cost and construction time within construction projects.

This paper is targeted toward determining a time-cost relationship model valid for the Youth Sport Center construction project. The model includes Change Orders categories; Work disciplines (Civil work, Electrical work, Structural work, Architectural work) and Project parties (Owner, Consultant, Contractor, Local Authorities).

\section{Literature review:}

A Change Order is the way used to compensate a contractor for additional costs or time on a construction project. A Change Order is an instrument prepared by the Engineer and signed by the owner, contractor, and engineer, each stating their agreement to any/all of the following: change(s) in work; the amount of the adjustment, if any, in the contract sum; and the extent of the adjustment, if any, in the contract time (AIA, 1997). There are two types of changes identified by A201 which include Change Orders and minor changes. The engineer's authority to order a change is limited to minor changes which by definition do not have any impact on price or time. All changes under the A201 process begin with Construction Change directives (CCD's) which may be used to direct the contractor to execute a change in the project. The contractor must perform the directed work under this process even if there is disagreement on price or time. Upon full agreement between the owner, contractor, and architect as evidenced by their signing, the CCD is converted to a change order.

Change Order Causes: Changes can originate from a number of sources, including the Owner, Architect, or the Contractor, as well as from the project itself. Complexity of construction project, a lack of coordination between design professionals, and misinterpreted design programs are the leading causes of change orders. Numerous authors have also identified and categorized potential causes of Change Orders. The Change Orders classified into three main categories: design errors and omissions, scope changes and unforeseen conditions. The design errors and omissions is 
responsible for $65 \%$ of changes, design changes (scope changes) account for $30 \%$ and unforeseen conditions account for 5\% (Ibbs 1997). Civetello, in his book “Contractor's Guide Orders”, identified many detailed causes of Change Orders and dedicates an entire chapter to "prospecting” for Change Orders (Civetello 2002). The majority of Change Orders result from errors or omissions in original contract documents. Sufficient time is not often given to Engineers and Architects to review historical data and develop construction documents, and therefore often resulting in errors and/or omissions. Although human error cannot be eliminated from the process, significant reductions of the same are possible. Changes made on the drawing board and in the design office are a lot cheaper and less time consuming to implement than those made in the field. Owners often issue bid package addenda when responding to formal questions from bidders (McCally, 1997). Current practice is to address or resolve issues with addenda or during the construction phase in lieu of the design phase. This slows the project down and distracts the parties from concentrating on the end goal. This forces them to deal with the changes at hand, which are commonly referred to as "putting out fires". Contractors and designers are so preoccupied with making corrections and tweaking designs; they spend much of their time concentrating on certain part of the project and lose sight of project as a whole. In current practice, architects and engineers rely on general notes in the contract documents to cover unanticipated changes which may lead to damages or delays sustained by the contractor. Subsequently the controller may misinterpret the documents (Kirsch, 2000).

\section{Research Scope and objectives:}

The study is undertaken in Egypt, a developing country; where the construction industry has its unique challenges. The construction industry faces high demand due to the need for development of a large array of project. The approach of this research was aimed to determine the impact of the main causes which lead to Change Orders occurrence in Sports construction projects during the project lifecycle stages. Furthermore, by developing a time-cost relationship model valid for Youth Sport Center construction project. The model includes Change Orders categories; Work disciplines (Civil work, Electrical work, Structural work, Architectural work) and Project parties (Owner, Consultant, Contractor, Local Authorities). 


\section{Research Methodology:}

The research methodology selected for this purpose comprised an extensive literature review, a questionnaire with a list of factors that were considered to have effects on Change Orders during all project life cycle stages of the sports construction projects, and a statistical analysis of the data. The questionnaire consisted of two sections; Section (1) solicited general information about the respondents, while Section (2) carried a total of 36 causes impacting change associated with Sports construction facilities. The likelihood of occurrence of these causes and the level of impact on each project objective was then determined.

\section{Survey Results:}

The main purpose of this investigation is not to identify a list of causes of change order but to determine the effect of each reason during all project lifecycles. Change Order probability occurrence may be described in quantitative terms such as low, moderate, and high. The degree of its cost impact probability is the effect on project objectives if the Change Order event occurs and also can be described in quantitative terms such as very low, low, moderate, high and very high. These two dimensions of change order are applied to specific factors (Owner, consultant, Contractor, Project Management, Local Authorities, Stakeholder and Force Majeure) not to the overall project. Analysis of Change Order using probability and consequences helps identify those Change Orders that should be managed aggressively. Hence, only the top twenty ranked ones are chosen as significance causes of change order. The result of the previous survey is presented in Table 1.

Table 1 the list of the 20 reason of change order and which project phase can give great cost impact on the construction project

\begin{tabular}{cll}
\hline No. & \multicolumn{1}{c}{ Project Phase } & \multicolumn{1}{c}{ Change Order Factor } \\
\hline 1 & $\begin{array}{l}\text { Direct and Manage project } \\
\text { Execution }\end{array}$ & $\begin{array}{l}\text { Additional client request during the course of } \\
\text { the project by the owner }\end{array}$ \\
2 & $\begin{array}{l}\text { Perform Integrated Change } \\
\text { Control }\end{array}$ & Contractor Financial Difficulties \\
3 & $\begin{array}{l}\text { Direct and Manage project } \\
\text { Execution }\end{array}$ & Unanticipated works by designer/ Consultant \\
4 & $\begin{array}{l}\text { Perform Integrated Change } \\
\text { Control }\end{array}$ & Stakeholders \\
5 & $\begin{array}{l}\text { Direct and Manage project } \\
\text { Execution }\end{array}$ & $\begin{array}{l}\text { Design revisions } \\
\text { Consultant }\end{array}$ \\
6 & $\begin{array}{l}\text { Direct and Manage project } \\
\text { Execution }\end{array}$ & Owner Financial difficulties \\
7 & Perform Integrated Change & Accelerated performance requested by the
\end{tabular}


Control owner

8 Direct and Manage project Following new or different schedule by the Execution Contractor

9 Perform Integrated Change

Following new or different schedule by the Control Contractor

10 Direct and Manage project

Unavailable specified products by the designer/ Consultant

11 Direct and Manage project

Stakeholders

Stakeholders

12 Monitor and Control

Project Work Stakeholders

13 Direct and Manage project

Execution owner

14 Monitor and Control

Initiated value engineering change by the owner

15 Direct and Manage project

Stopped, disrupted or interrupted work by the owner

16 Monitor and Control

Unavailable specified products by the designer/ Consultant

17 Direct and Manage project

Design deficiency by the designer/ Consultant

18 Perform Integrated Change

Control
Direct and Manage project

19 Execution

Lack of skilled labor

Third party permits

20 Monitor and Control

Third party permits

The most frequently and costly Change Orders were generated due to changes attributed to the owner 32\%, while the second cause was changes attributed to the Designer/ Consultant 28\%, the third cause in order was changes attributed to the Owner $12 \%$, the forth cause was changes attributed to Project Management $9 \%$, the fifth cause was changes attributed to Local Authorities 9\%, the sixth cause was changes attributed to stakeholders $6 \%$ and the last one was changes attributed to Force Majeure. The Changes attributed to the Owner was considered to have the greatest impact on sports facilities construction project, as shown in Figure 1. 


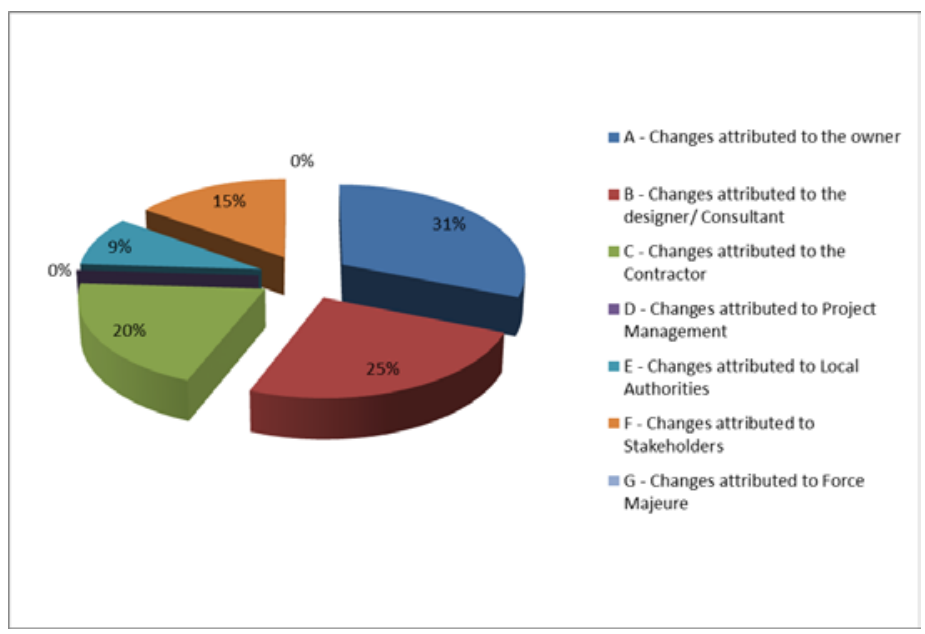

Fig.1 Percentage of frequency for the causes which gives great impact on the project

\section{Empirical Model for Prediction of Construction Time}

The number of Change Orders that have an impact on actual construction time for the type of project, causing a higher number of Change Orders results in a longer duration of construction. This is not very surprising in an Egyptian construction scenario, as it takes a long time to process a Change Order due to tedious bureaucratic procedures.

As presented before, the duration of project time for a construction project is basically a function of its total cost. It provides a basis for all parties concerned with the construction process to establish fairly accurate probable project duration, in days, given the estimated cost of the project. The authors also analyzed the overruns on cost and time which provided a measure on the accuracy of the industry's time and cost predictions.

The curves that best fit the Additive Change Order quantitative variables attributed to the Youth Sport Center Construction Projects are presented in Figure 5.30 to 5.60 presents the curve that best-fit the power equation between the variables original cost and cost increasing variables, initial estimated duration and final duration attributed to different variables.

\section{The time-cost relation:-}

- Empirical Model for Prediction of Construction Time Related to Estimated Cost . $T_{a}=0.0261 C_{e}^{0.6345}$$$
R^{2}=0.869
$$ 
- Empirical Model for Prediction of Construction Time Related to Actual Cost. $T_{a}=0.0294 C_{e}^{0.619}$

$R^{2}=0.7923$

- Empirical Model for Prediction of Construction Cost Related to Estimated Time.

$$
T_{e}=0.0273 C_{e}^{0.6209} \quad R^{2}=0.8051
$$

- Empirical Model for Prediction of Construction Cost Related to Estimated Cost.
$C_{a}=3.3858 C_{e}^{0.9254}$
$R^{2}=0.8941$

- Empirical Model for Prediction of Construction Time Related to Estimated Time.

$T_{a}=1.2307 T_{e}^{0.9693} \quad R^{2}=0.9301$

Where:-

$\boldsymbol{T}_{\boldsymbol{e}} \quad$ is the estimated construction duration in days.

$\boldsymbol{T}_{\boldsymbol{a}}$ is the Actual construction duration in days.

$\boldsymbol{C}_{\boldsymbol{e}}$ is the estimated construction cost in EGP.

$\boldsymbol{C}_{\boldsymbol{a}}$ is the Actual construction cost in EGP.

$\boldsymbol{R}^{2} \quad$ A widely used measure for checking the predicative efficacy of a model is its coefficient of determination. Perfect relation is said to exist between the dependent and independent variables if $\mathrm{R}^{2}$ is 1 and no relationship exists between the dependent and independent variables if $\mathrm{R}^{2}$ is 0 .

Empirical Model for Prediction of Construction Cost and/or Time Related to Estimated Cost and/or Time

$$
\begin{aligned}
C_{a} & =A_{c} C_{e}{ }^{B c} \\
T_{a} & =A_{t} C_{e} e^{B t}
\end{aligned}
$$

\section{Where:-}

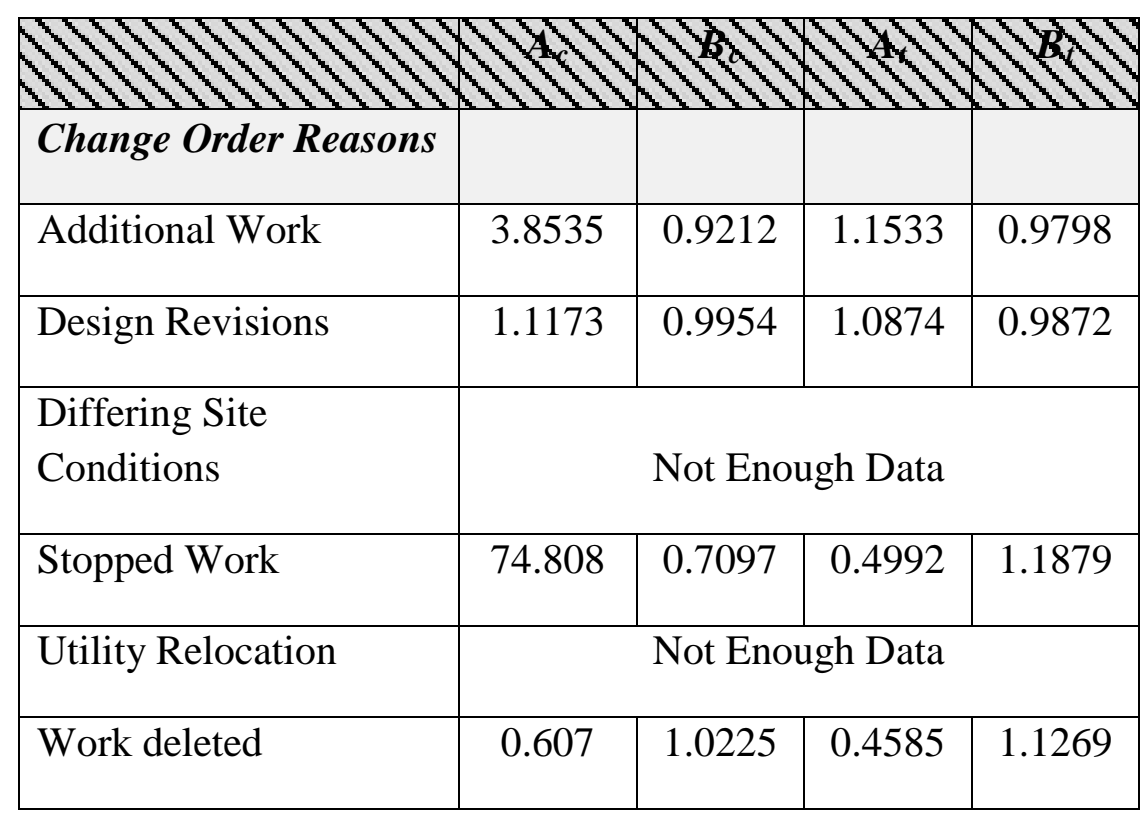




\begin{tabular}{|l|c|c|c|c|}
\hline Work Discipline & & & & \\
\hline Civil Work & 2.5733 & 0.944 & 1.1371 & 0.9288 \\
\hline Electrical Work & 3.4536 & 0.9207 & 1.5094 & 0.9288 \\
\hline Structural Work & 483572 & 0.7472 & 1.0189 & 0.9967 \\
\hline Architectural Work & 0.0127 & 1.335 & 1.5151 & 0.9596 \\
\hline
\end{tabular}

\begin{tabular}{|l|c|c|c|c|}
\hline Participating Parties & & & & \\
\hline Owner & 2.7177 & 0.9445 & 1.0683 & 0.9934 \\
\hline Consultant & \multicolumn{4}{|c|}{ Not Enough Data } \\
\hline Contractors & 8.814 & 0.8503 & 1.2234 & 0.9626 \\
\hline Local Authorities & 0.2078 & 1.133 & 0.8078 & 1.1009 \\
\hline
\end{tabular}

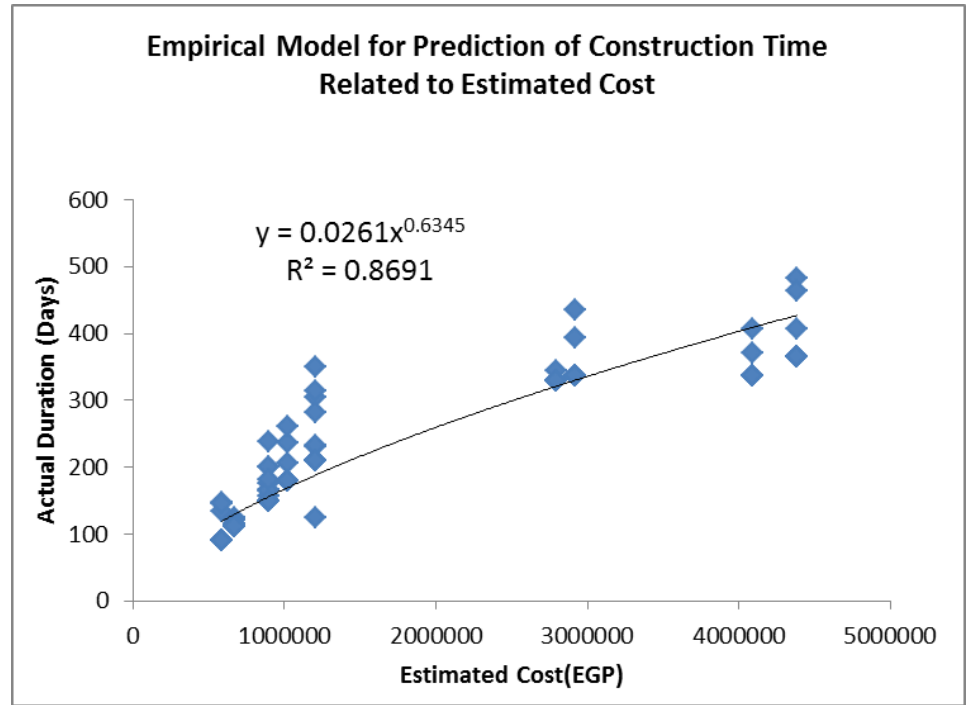

Fig. 2 The relationship between estimated cost and actual duration 


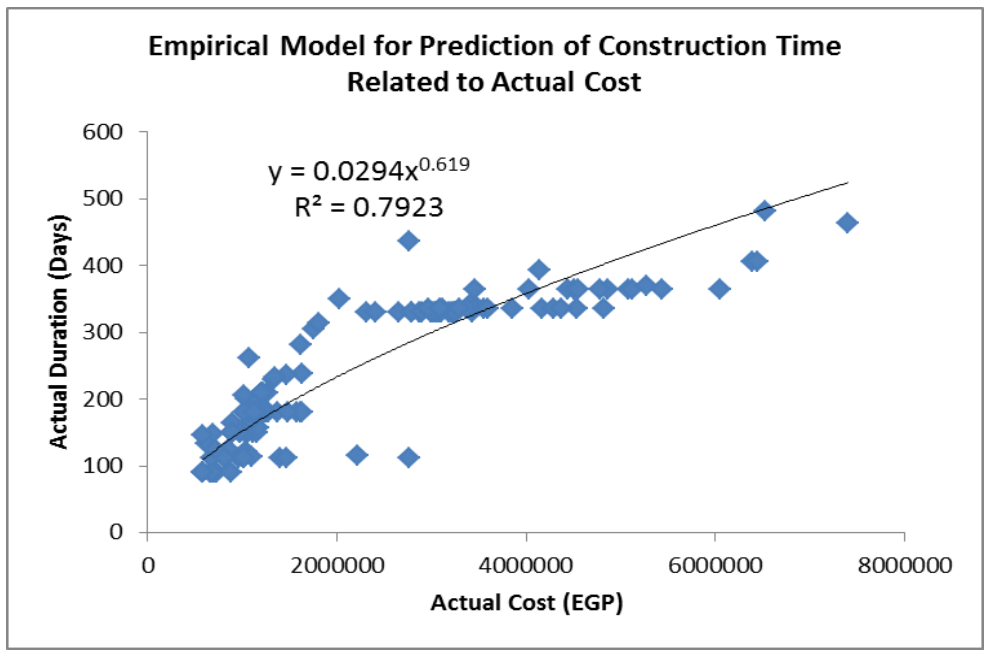

Fig.3The relationship between actual cost and actual duration

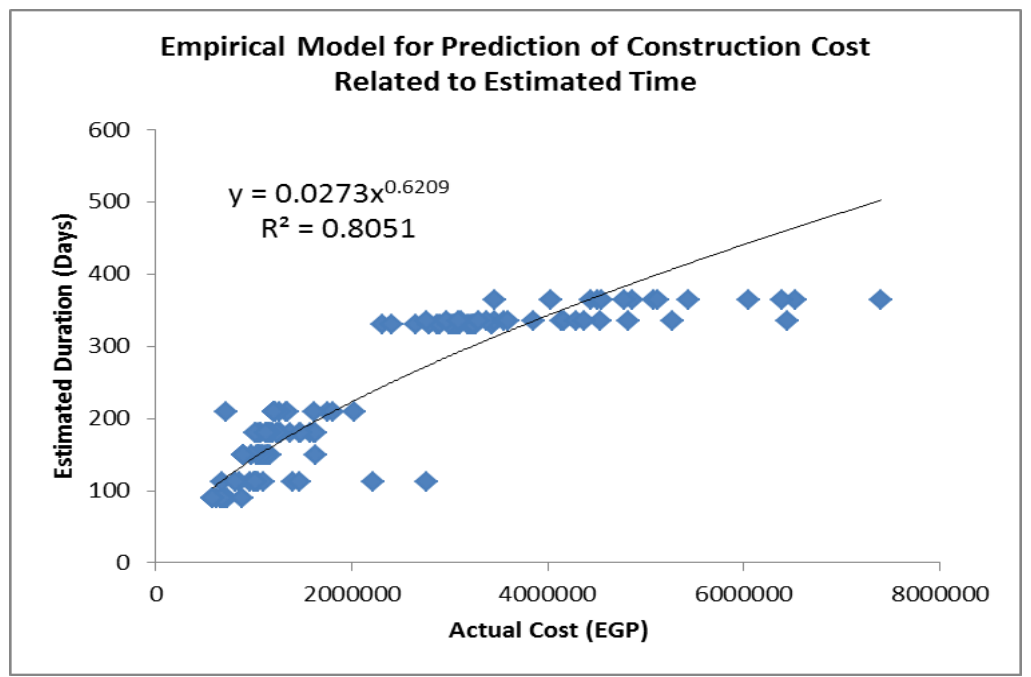

Fig.4 The relationship between actual cost and estimated duration

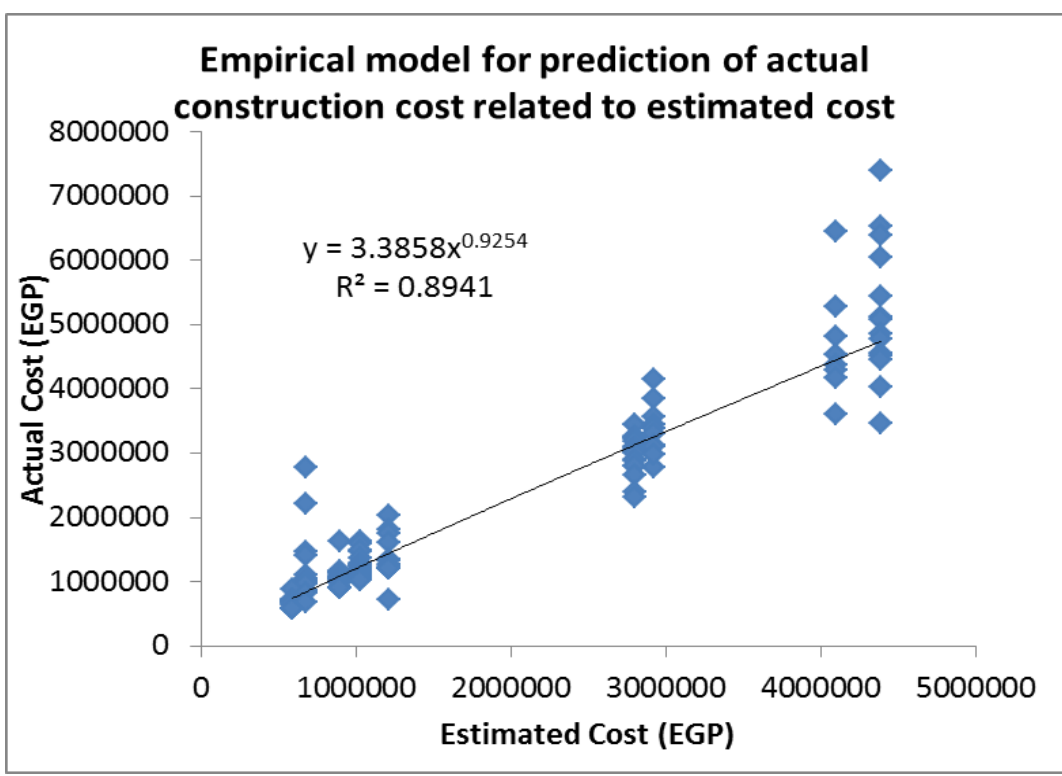

Fig.5 The relationship between estimated cost and actual cost 


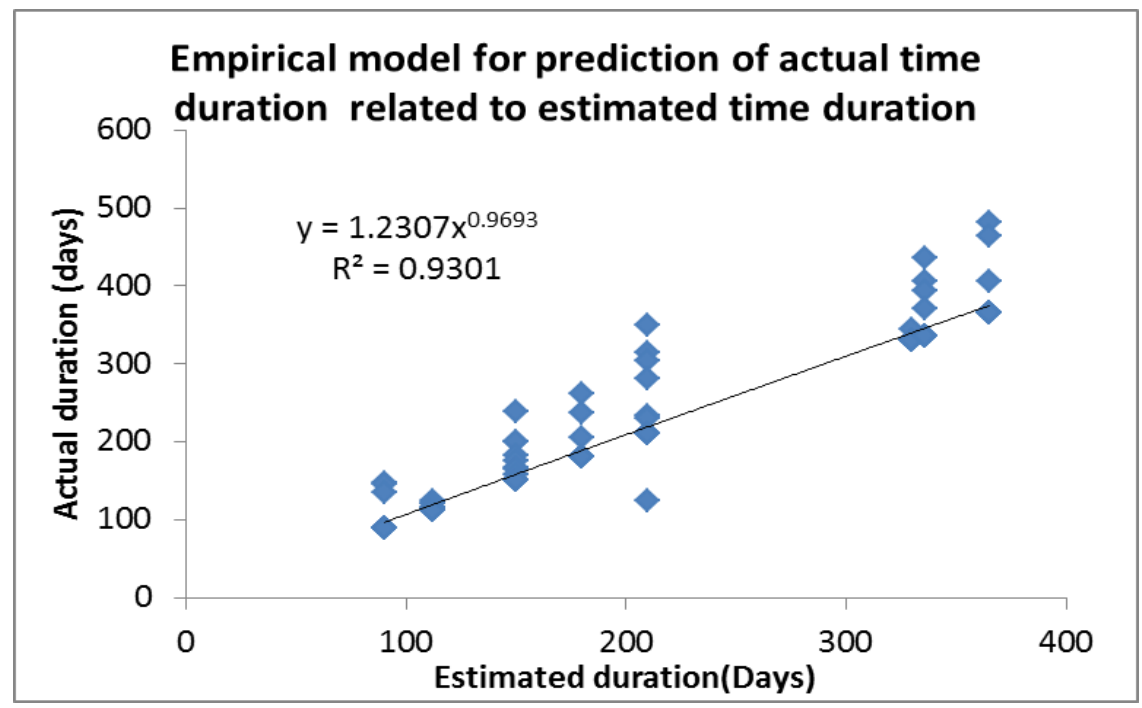

Fig.6 The relationship between estimated duration and actual duration

\section{Conclusions:}

A great majority of the Change Orders were Additive Change Orders resulting in an average cost increasing of $5.3 \%$. On the other hand Deductive orders had insignificant cost reduction, the cost reduction due to Deductive Change Order was 7.5\% from the net cost Increasing. Although most of the Additive Change Orders resulted in cost increasing only, the average time extension was $6.83 \%$ of the original project duration.

There is a moderate degree of variation when the relationships between cost increasing and original project cost, categorized using qualitative variables such as reasons for Change Orders, were examined. It was observed that quadratic relationships provide high correlation. Furthermore, it was found that as original project cost increases, cost increasing also increases. On the other hand, the range of the examined data (related to type and cost) was limited which may affect the stability of the relationships when they are projected beyond this limited range of data.

There is a relationship between project cost and construction time within construction projects. This study tried to develop a time-cost relationship model to be valid on the Youth Sport Center construction project. The model was included Change Orders categories; Work disciplines (civil work, electrical work, structural work, architectural work) and Project parties (Owner, Consultant, Contractors, Local Authorities). 


\section{References:}

(1)AIA (1997) “General Conditions of the Contract for Construction,” Document A201, American Institute of Architects, www.aiane.org/Info/documents/docSynopsis/synopsis-10.htm.

(2)Wallwork, J.W. (2001). "Change Order Evaluation \& Resolution Approach.” Cost Engineering. October 2001. Vol. 43/No.(10): 19.

(3)Diekmann, J. \& Nelson, M.C. (1985). "Construction claims: frequency and severity." ASCE Journal of Construction Engineering and Management, Vol. 122, No.1.

(4)Jacob, R.C., and Richter, I. (1978b). “Guidelines for constructive Change Orders” Construction Contracting. November 1978 Vol. 60/No.11.

(5)Clark, W.G. (1990).”Claims Avoidance \&resolution”. AACE International Traansactions,1990. R.11.

(6)Ibbs William (1997).” Quantitative Impacts of Change on Project Cost \& Schedule”. ASCE Journal of Construction Engineering and Management. 123(3). September 1997.123(3) 8-011.

(7)Civitello, Jr. A.M. (2002).”Contractors Guide to Change Orders.” 2nd Ed., Prentice hall, New York.

(8)Fayek, A.R., and Nkuah, M.Y. (2002). "Analysis of Change Order Markup Allowances on Stipulated Price Building Contracts”. Cost Engineering. January 2002. Vol. 44/No.(1):28.

(9)Ehrenreich - Hansen Fritz. (1994). “Change order Management for Construction Projects”. Cost Engineering. Vol. 36. No.(3):.March. Vol. 36/No.3.25.

(10) McCally Bob M. (1997). 'Change Order management”. AACE International Transactions of the 41st Annual Meeting.

(11) Kirsch, John J., (2000). “Differing Site Conditions Costs?” 